\title{
Cerebral hemispheres serve as two channels for visual information processing
}

\author{
K. GEOFFREY WHITE and ALAN B. SILVER \\ Victoria University of Wellington, New Zealand
}

\begin{abstract}
Grid patterns or CVC trigrams were presented tachistoscopically in the left or right visual fields or concurrently in both visual fields. There were fewer errors in identifying both grids and CVCs when a grid on the left was paired with a CVC on the right than when a CVC on the left was paired with a grid on the right. The result indicated that when each hemisphere received the type of stimulus material, spatial or verbal, for which its function was specialized, they served as separate channels and processing accuracy was maximal.
\end{abstract}

Experimental research on laterality differences in the perception of visual and auditory stimuli indicates a basic assymetry in cerebral hemispheric functioning (Allard, 1972; Milner, 1971; White, 1969). The right hemisphere is specialized for processing nonverbal or spatial material whereas the left hemisphere processes mainly verbal material. Owing to contralateral representation in the central nervous system, stimuli presented in the left visual field are directed to the right hemisphere, and stimuli in the right visual field are directed to the left hemisphere. Hemispheric assymetry is demonstrated in experiments which involve presenting spatial or verbal stimuli in the left or right visual fields. Reaction times for comparison between the physical or spatial aspects of letters are much faster when the letters are presented in the left visual field. But for comparisons between the verbal or nominal aspects, reaction times are faster when the letters are presented in the right visual field (Cohen, 1972; Geffen, Bradshaw, \& Nettleton, 1972).

In the present experiment, verbal stimuli were presented in one visual field while spatial stimuli were simultaneously presented in the other. It was expected that accuracy of identification of the stimuli would be greater for verbal stimuli in the right visual field and spatial stimuli in the left than for the converse situation. That is, processing accuracy should be maximal when each hemisphere analyzes stimuli appropriate to its function.

\section{METHOD}

Verbal stimuli were four CVC trigrams (bem, bov, gom, guk) with equal meaningfulness and association value (Noble, 1961) printed in uppercase Letraset 286 on white card. A trigram was $21 \mathrm{~mm}$ wide overall. Each of four grid patterns consisted of a 3 by 3 matrix $(21 \mathrm{~mm} \times 21 \mathrm{~mm})$ containing a circle in each of three different cells. Numbering the cells from left to right and top to bottom, cells containing circles were $1,5,6 ; 8,9,2 ; 3,4$, 6; and 1, 7, 2 for each of the four grids, respectively. Grids and CVCs were drawn on the right or left of each stimulus card such that the distance between center and the inside edge of a stimulus subtended $2.5 \mathrm{deg}$ visual angle.
Stimuli were presented in a three-field Gerbrands tachistoscope either singly in the left or right visual field, or doubly in both visual fields, one stimulus in each hemifield. In the double-stimulus pattern, either a grid on the left was paired with a CVC on the right, or a CVC on the left was paired with a grid on the right. Grids and CVCs were on the left or right equally often, and each grid was paired with each CVC in the 32 double-stimulus displays. The double-stimulus displays were randomized with 32 single-stimulus displays (grid or CVC on the left or right) in order to minimize attentional bias to either hemifield. Luminance of the stimulus field was approximately $7 \mathrm{~cd} / \mathrm{m}^{2}$.

There were 19 right-handed subjects (six males) with normal or corrected-to-normal vision. Each subject participated in about 12 practice trials and was familiarized with the grid and CVC stimuli before the 64 test trials. On each trial, a 2-sec black fixation spot was immediately followed by a 50 -msec stimulus pattern, after which the subject was required to write down which patterns he had seen. Prior fixation of the central fixation spot in conjunction with brief lateral stimulus presentation insured that the stimuli were directed to the left or right hemispheres.

\section{RESULTS AND DISCUSSION}

Mean identification errors for the single-stimulus and double-stimulus displays are given in Table 1 . The mean square-root transformed error frequencies were submitted to repeated measures analyses of variance. More errors were made in identifying grid patterns than in identifying CVCs for both single-stimulus displays $[F(1,18)=10.45, p<.01]$ and double-stimulus displays $[F(1,18)=40.93, p<.001]$. Overall stimuli in the left visual field were identified just as accurately as the right visual field for both display types. There was therefore no overall bias in identifying stimuli from one or the other hemifield. In the single-stimulus displays, there was a greater mean error in identifying CVCs in the left visual field than in the right, and in identifying grids in the right visual field than in the left. This interaction failed to reach significance $[F(1,18)=2.30, p>.05]$, presumably because there were very few errors altogether in the single-stimulus displays.

Most importantly, the interaction between visual field and stimulus type was significant for the double-stimulus 
Table 1

Mean Identification Error Frequencies

\begin{tabular}{|c|c|c|}
\hline & $\begin{array}{c}\text { Left Visual } \\
\text { Field } \\
\end{array}$ & $\begin{array}{c}\text { Right Visual } \\
\text { Field }\end{array}$ \\
\hline & \multicolumn{2}{|c|}{ Double-Stimulus Displays } \\
\hline $\begin{array}{l}\text { "Appropriate" } \\
\text { Hemispheres }\end{array}$ & 3.48 (Grids) & .66 (CVCs) \\
\hline \multirow{3}{*}{$\begin{array}{l}\text { "Inappropriate" } \\
\text { Hemispheres }\end{array}$} & 1.72 (CVCs) & 4.48 (Grids) \\
\hline & \multicolumn{2}{|c|}{ Single-Stimulus Displays } \\
\hline & $\begin{array}{l}.73 \text { (Grids) } \\
.39 \text { (CVCs) }\end{array}$ & $\begin{array}{l}.29 \text { (CVCs) } \\
.75 \text { (Grids) }\end{array}$ \\
\hline
\end{tabular}

displays $[F(1,18)=8.12, p<.025]$. Thus, in the situation where a grid pattern was directed to one hemisphere, and a CVC was simultaneously directed to the other, identification was more accurate when spatial stimuli were processed by the right (spatial) hemisphere and verbal spatial and verbal stimuli were processed by "inappropriate" hemispheres.

The interaction between visual field and stimulus type in the double-stimulus displays suggests that when each hemisphere receives the type of stimulus material for which its function is specialized, the hemispheres serve as partially separate information processing channels. If each hemisphere receives material for which it is not specialized, accuracy of analyzing or processing that material decreases. The notion that the hemispheres act as separate channels has further support from the result that dividing the processing load between hemispheres allows more rapid and accurate processing. When a comparison is required between a pair of visually presented digits, reaction times for the comparison are faster when one digit is directed to the left hemisphere and the other to the right hemisphere than when both digits are direct to just one hemisphere (Davis \& Schmit, 1971). For double-stimulus displays, therefore, the hemispheres act as separate channels in the processing of visual information, and further, processing accuracy is maximal when each channel analyzes stimuli appropriate to its function.

\section{REFERENCES}

Allard, F. Cerebral dominance. In M. Coltheart (Ed.), Readings in cognitive psychology. Toronto: Holt, Rinehart, and Winston. 1972.

Cohen, G. Hemispheric differences in a letter classification task. Perception \& Psychophysics, 1972, 11, 139-142.

Davis, R., \& Schmit, V. Timing the transfer of information between hemispheres in man. Acta Psy chologica, 1971, 35, 335-346.

Geffen, G., Bradshaw, J. L., \& Nettleton, N. C. Hemispheric assymetry: Verbal and spatial encoding of visual stimuli. Journal of Experimental Psy chology, 1972, 95, 25-31.

Milner, B. Interhemispheric differences in the localization of psychological processes in man. British Medical Bulletin, $1971,27,272-277$.

Noble, C. E. Measurements of association value (a), rated associations ( $\left.a^{\prime}\right)$, and scaled meaningfulness $\left(\mathrm{m}^{\prime}\right)$ for the $2100 \mathrm{CVC}$ combinations of the English alphabet Psychological Reports, 1961, 8, 487-521.

White, M. J. Laterality differences in perception: A review. Psychological Bulletin, 1969, 72, 387-405.

(Received for publication October 17, 1974.) 